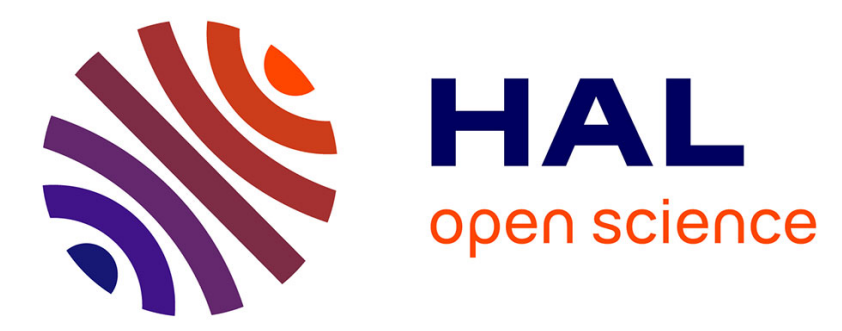

\title{
Leaching of radio-oxidized poly(ester urethane) water-soluble molecules characterization
}

\author{
E. Fromentin, M. Pielawski, D. Lebeau, S. Esnouf, M. Ferry, F. Cochin, N.
} Caron, S. Legand

\section{- To cite this version:}

E. Fromentin, M. Pielawski, D. Lebeau, S. Esnouf, M. Ferry, et al.. Leaching of radio-oxidized poly(ester urethane) water-soluble molecules characterization. 13th Tihany Symposium on Radiation Chemistry, Aug 2015, Balatonalmadi, Hungary. cea-02489486

\section{HAL Id: cea-02489486 https://hal-cea.archives-ouvertes.fr/cea-02489486}

Submitted on 24 Feb 2020

HAL is a multi-disciplinary open access archive for the deposit and dissemination of scientific research documents, whether they are published or not. The documents may come from teaching and research institutions in France or abroad, or from public or private research centers.
L'archive ouverte pluridisciplinaire HAL, est destinée au dépôt et à la diffusion de documents scientifiques de niveau recherche, publiés ou non, émanant des établissements d'enseignement et de recherche français ou étrangers, des laboratoires publics ou privés. 
DE LA RECHERCHE A L' IND UST R IE
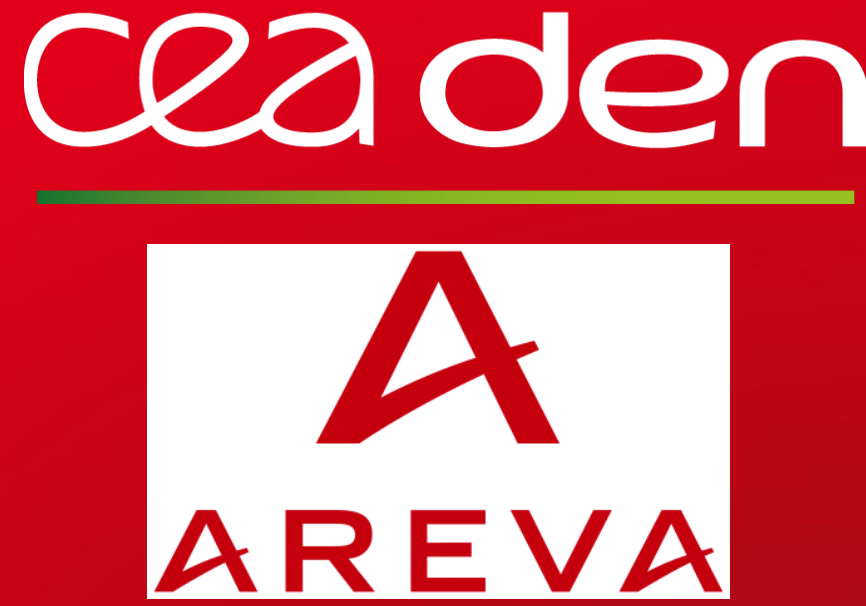

Leaching of radio-oxidized poly(ester urethane): water-soluble molecules characterization
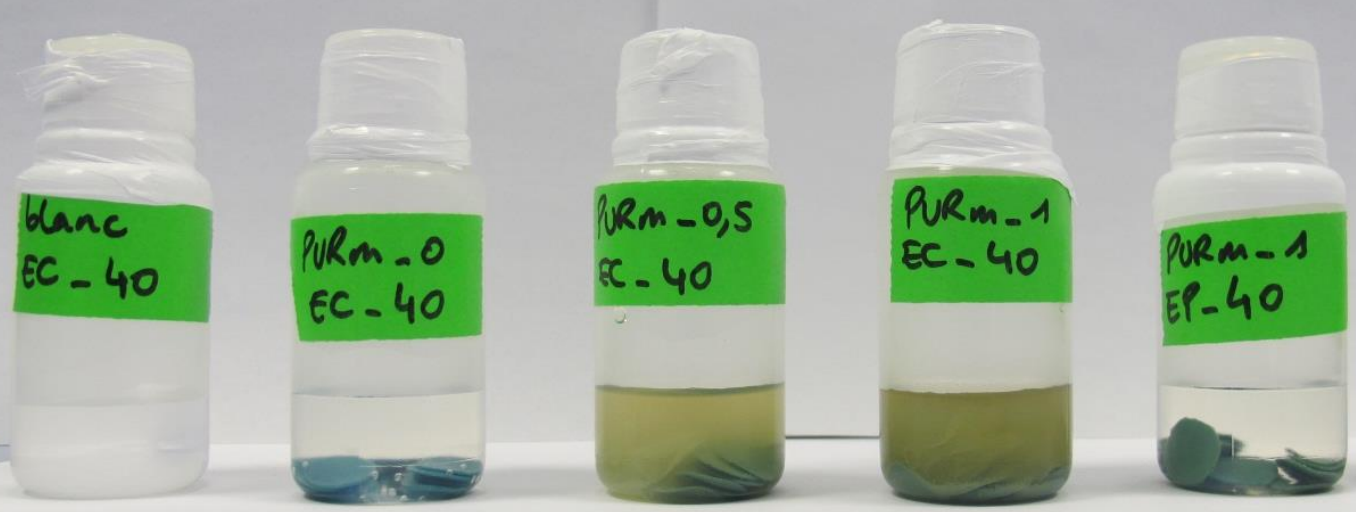

E. Fromentin ${ }^{1 *}$, M.Pielawski ${ }^{1}$, D.Lebeau ${ }^{1}$, S. Esnouf ${ }^{1}$, M.Ferry $^{1}$, F.Cochin ${ }^{2}$, N.Caron ${ }^{3}$ and S. Legand ${ }^{1}$

${ }^{1}$ CEA, DEN, DPC, SECR, LRMO, F-91191 Gif-sur-Yvette, France.

2 AREVA NC DOR/RDP, 1 place Jean Millier, F-92084 La Défense Cedex, France.

${ }^{3}$ CEA, DEN, DPC, F-91191 Gif-sur-Yvette, France.

13th Tihany Symposium on Radiation Chemistry $2^{\text {th }}$ August-3 ${ }^{\text {rd }}$ September 2015 


\section{ceaden INTRODUCTION}

A repository disposal diagram:

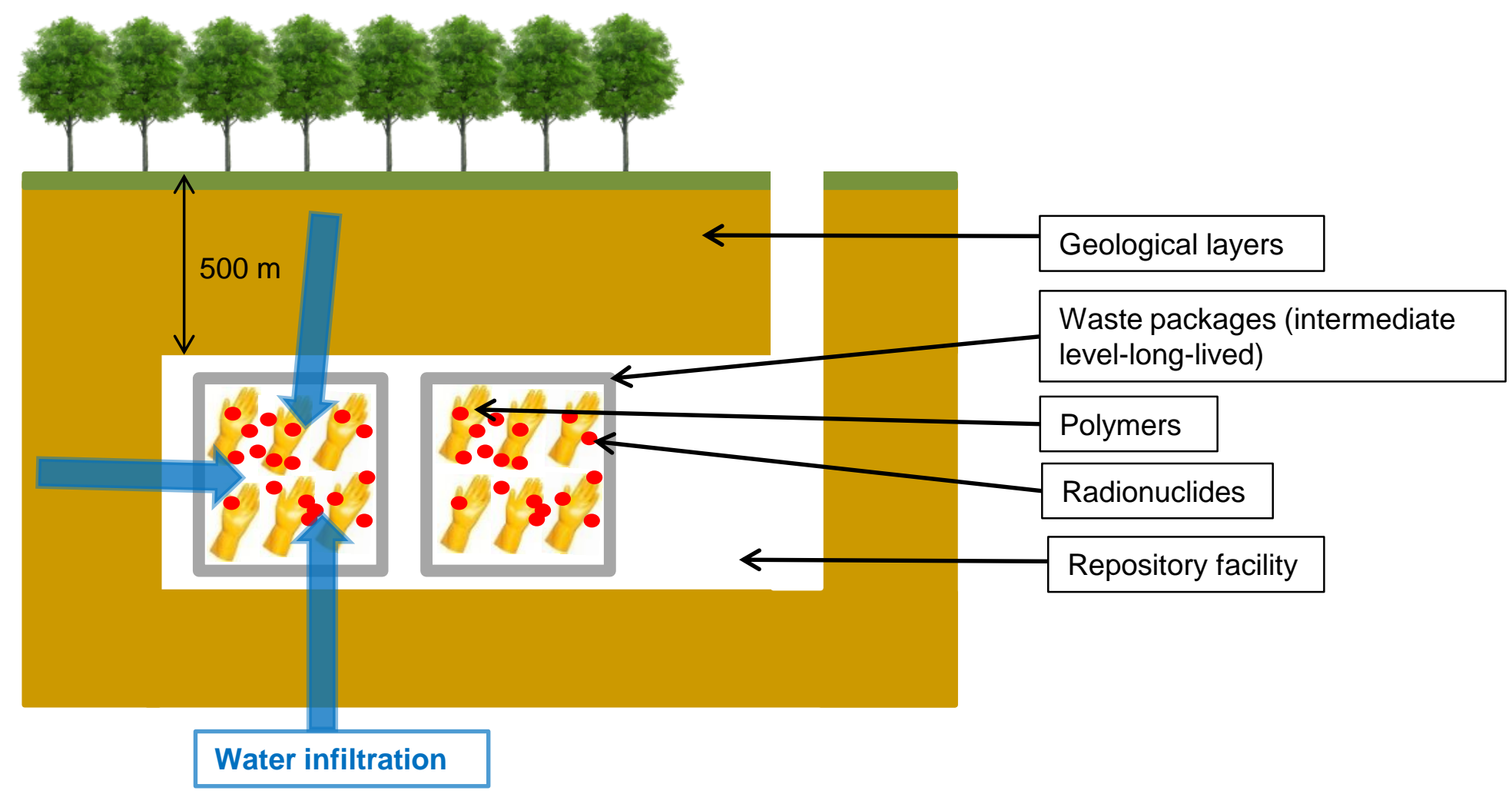

Long-term degradation ( $\approx 1,000$ years): radiolysis and alkaline hydrolysis

Question: what is the effect of water-soluble products on the radionuclides mobility? 


\section{ceaden INTRODUCTION}

\section{Considered polymer}

- Poly(ester urethane) (PUR)

- Used as glove for glove boxes
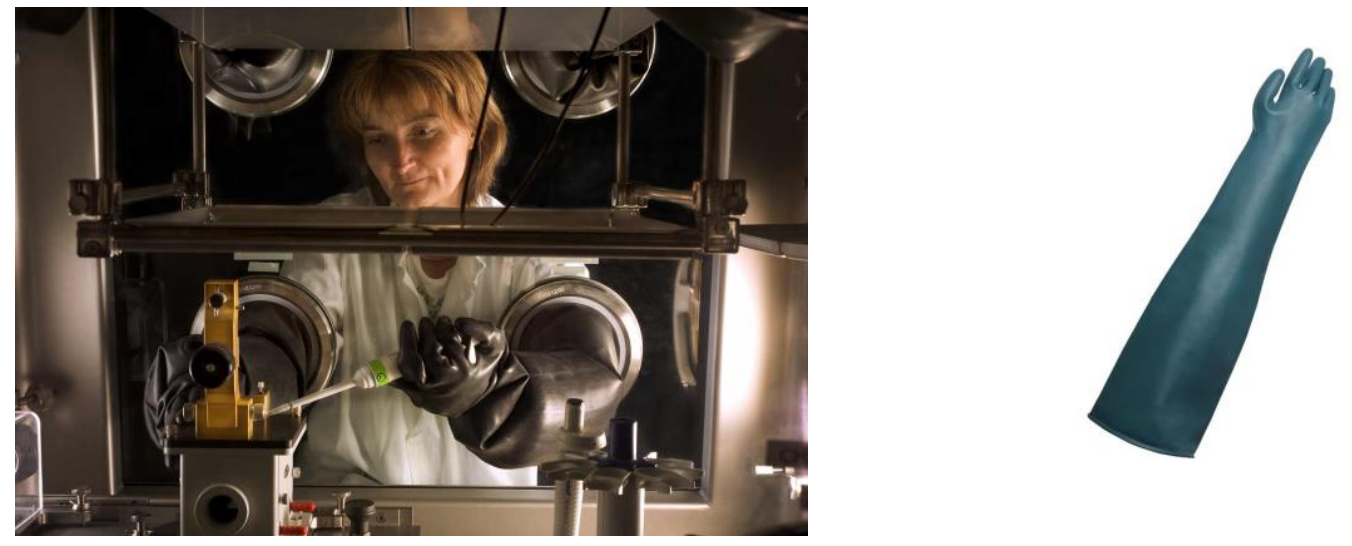

- Composed of 3 segments issued from these molecules

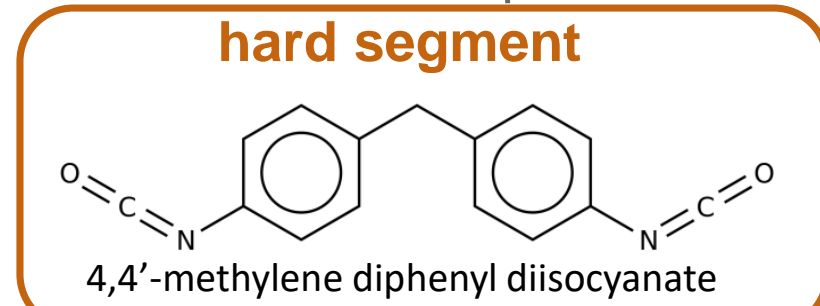

4,4'-methylene diphenyl diisocyanate
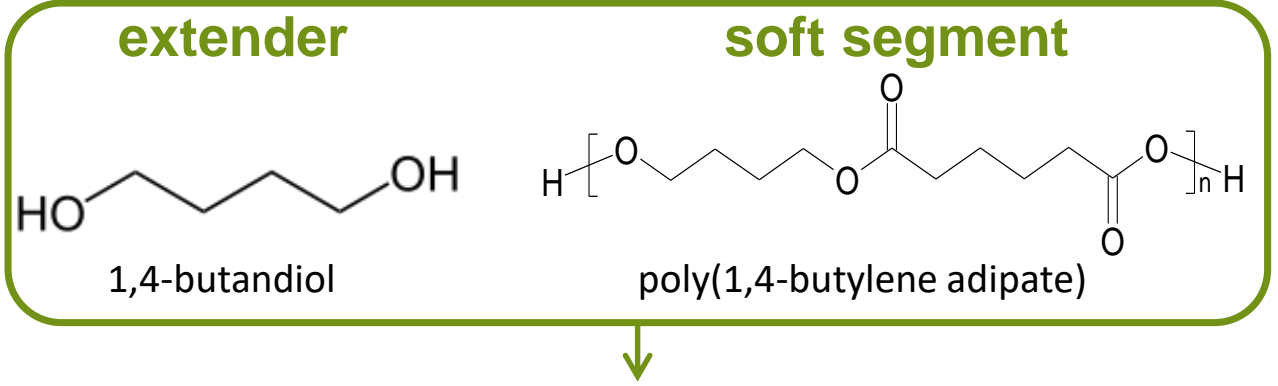

$25.5 \%_{w}$

$+8.9 \%$ inorganic fillers

$63.4 \% \%_{w}$

$+1,8 \%$ cross linking agents

$+0,4 \%$ pigments 


\section{ceaden INTRODUCTION}

\section{Objectives}

- Characterizing and quantifying water-soluble molecules created by the alkaline hydrolysis of the non-irradiated and irradiated PUR at different doses

- Understanding the degradation mechanisms

- PUR under radiolysis

- Irradiated PUR under hydrolysis

I Identifying the products than can complex with the radionuclides

- Being able to model the complexant release kinetics 


\section{ceaden INTRODUCTION}

\section{Objectives}

Characterizing and quantifying water-soluble molecules created by the alkaline hydrolysis of the non-irradiated and irradiated PUR at different doses

Understanding the degradation mechanisms

- PUR under radiolysis

- Irradiated PUR under hydrolysis

I Identifying the products than can complex with the radionuclides

- Being able to model the complexant release kinetics 


\section{ceaden MATERIALS}

\section{A two-step preparation}

- 1 $1^{\text {st }}$ step: PUR is irradiated under air using $\gamma$ rays by IONISOS $\left({ }^{60} \mathrm{Co}\right.$ source), dose rate: $~ 0.7$ kGy. $\mathrm{h}^{-1}$, doses: 4 MGy ( 8 months irradiation) and 10 MGy ( 20 months irradiation)

E $2^{\text {nd }}$ step: non-irradiated and irradiated PUR is then hydrolyzed and the $\mathrm{pH}$ is maintained constant $=$ leaching
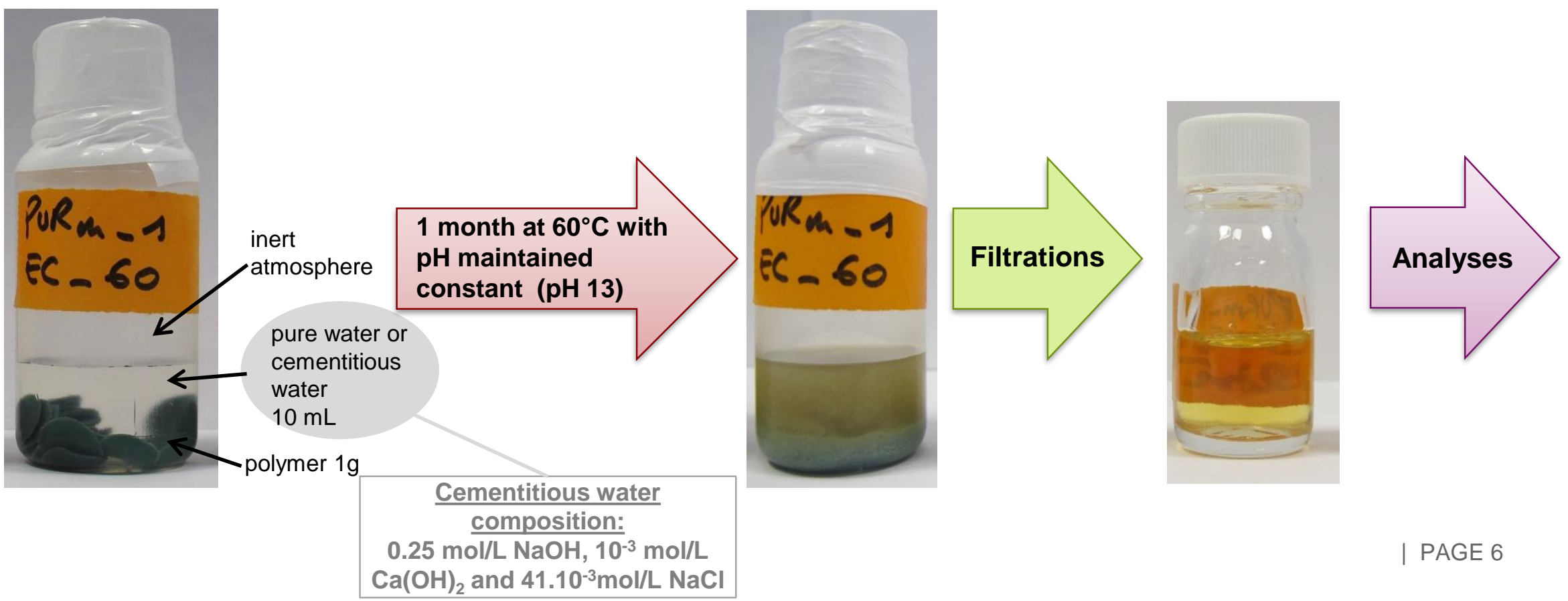


\section{Analytical approach}

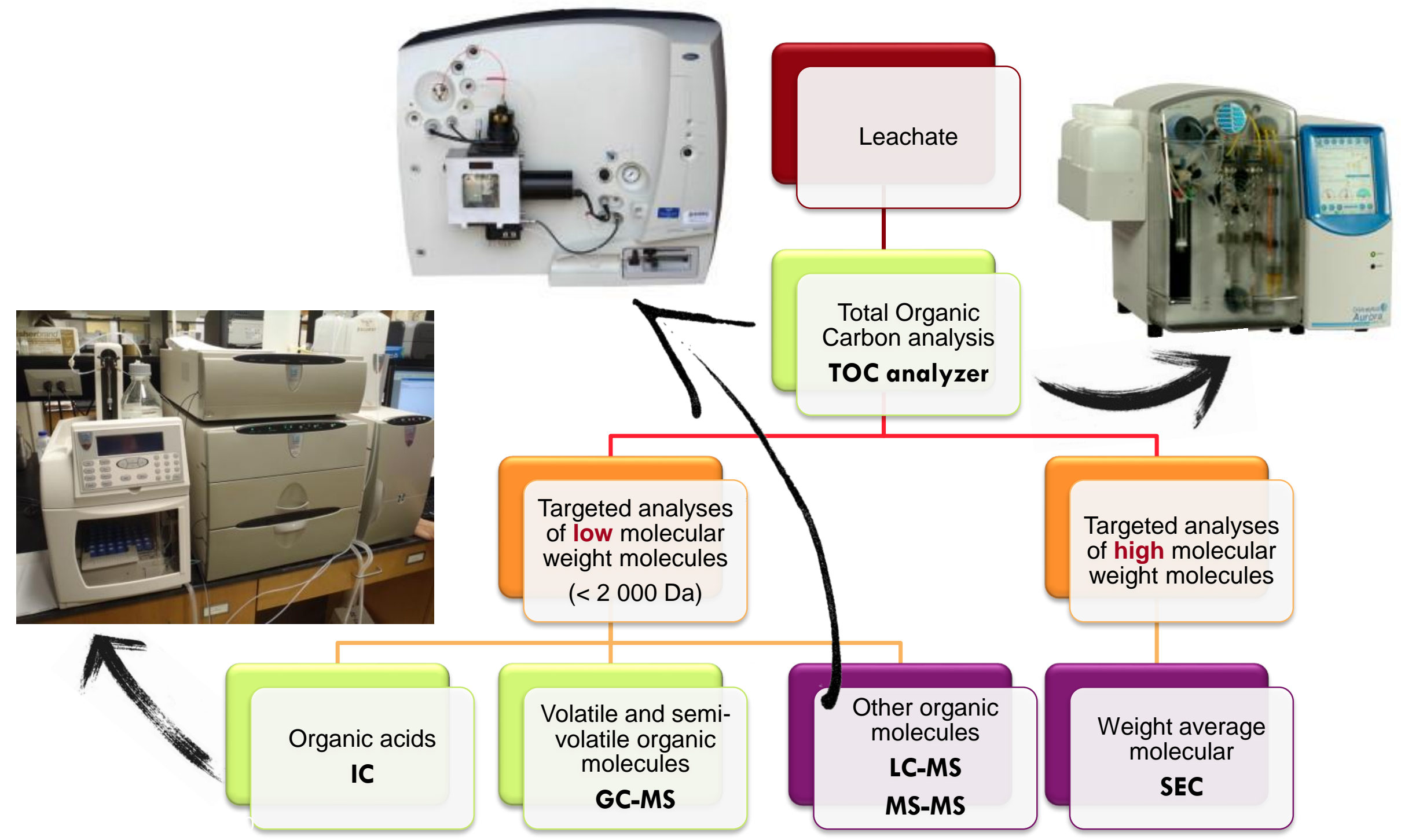




\section{ceaden}

\section{RESULTS AND DISCUSSION}

\section{Gas chromatography-mass spectrometry}

Molecules detected in the 10 MGy irradiated PUR leachate in pure water

- Some molecules are directly identifiable in the polymer formula :<smiles>CCCCC(=O)O</smiles>

pentanoic acid<smiles>CCCC(=O)O</smiles>

butanoic acid<smiles>CCC(=O)O</smiles>

propionic acid

soft segment

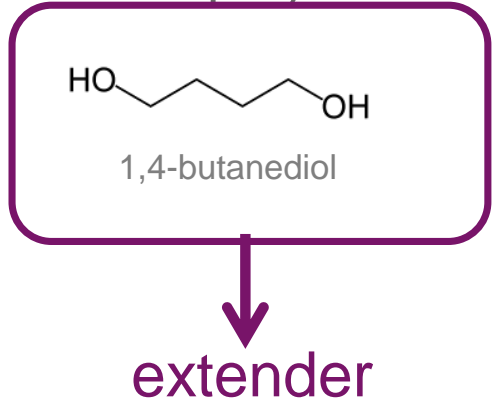

extender
訨

4,4'-diaminodiphenylmethane

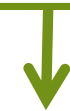

hard segment

- Other molecules are due to chain scission or chain ends radio-oxidation, or due to ester groups hydrolysis and rearrangements.
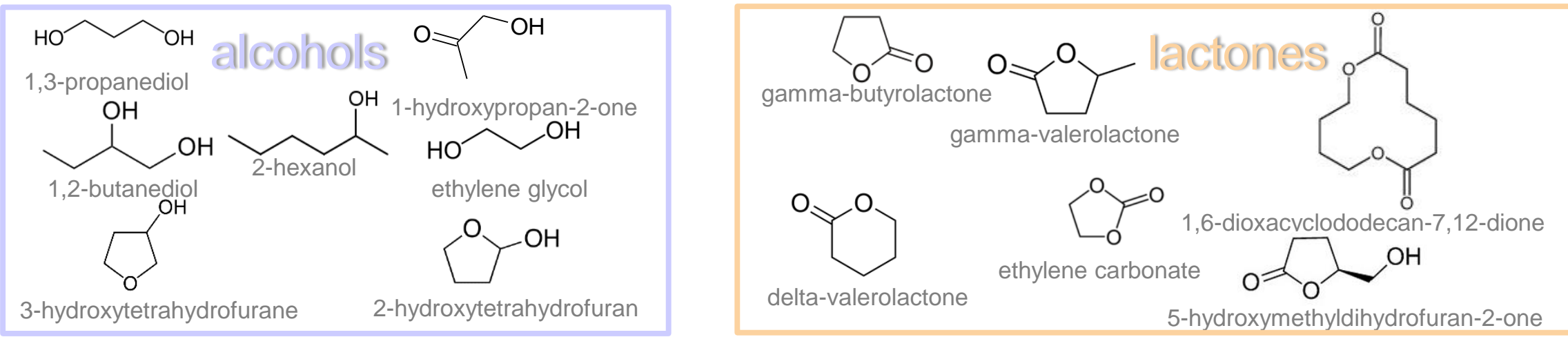

propyl 3-methylbutanoate diisopropyl adipate




\section{ceaden}

\section{RESULTS AND DISCUSSION}

\section{Gas chromatography-mass spectrometry}

Molecules detected in the 10 MGy irradiated PUR leachate in pure water

- Some molecules are directly identifiable in the polymer formula :

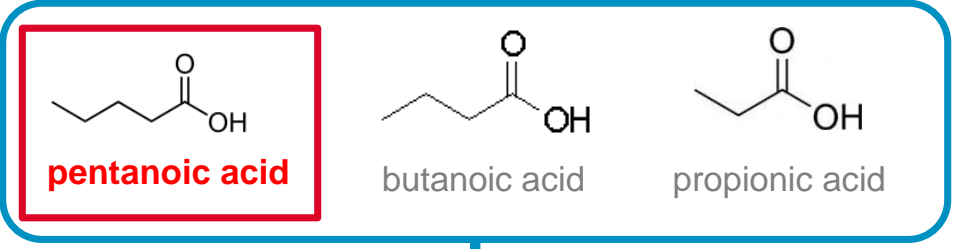

soft segment

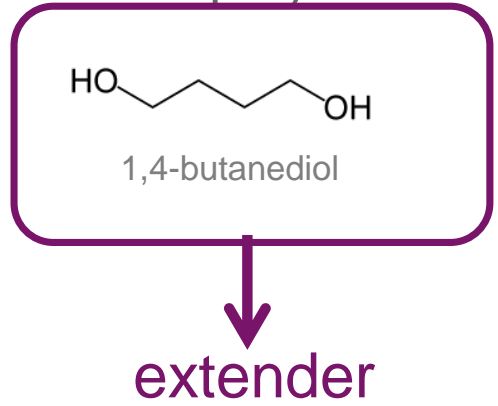

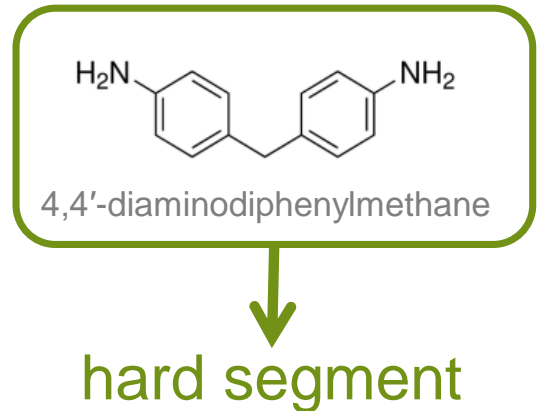

- Other molecules are due to chain scission or chain ends radio-oxidation, or due to ester groups hydrolysis and rearrangements.
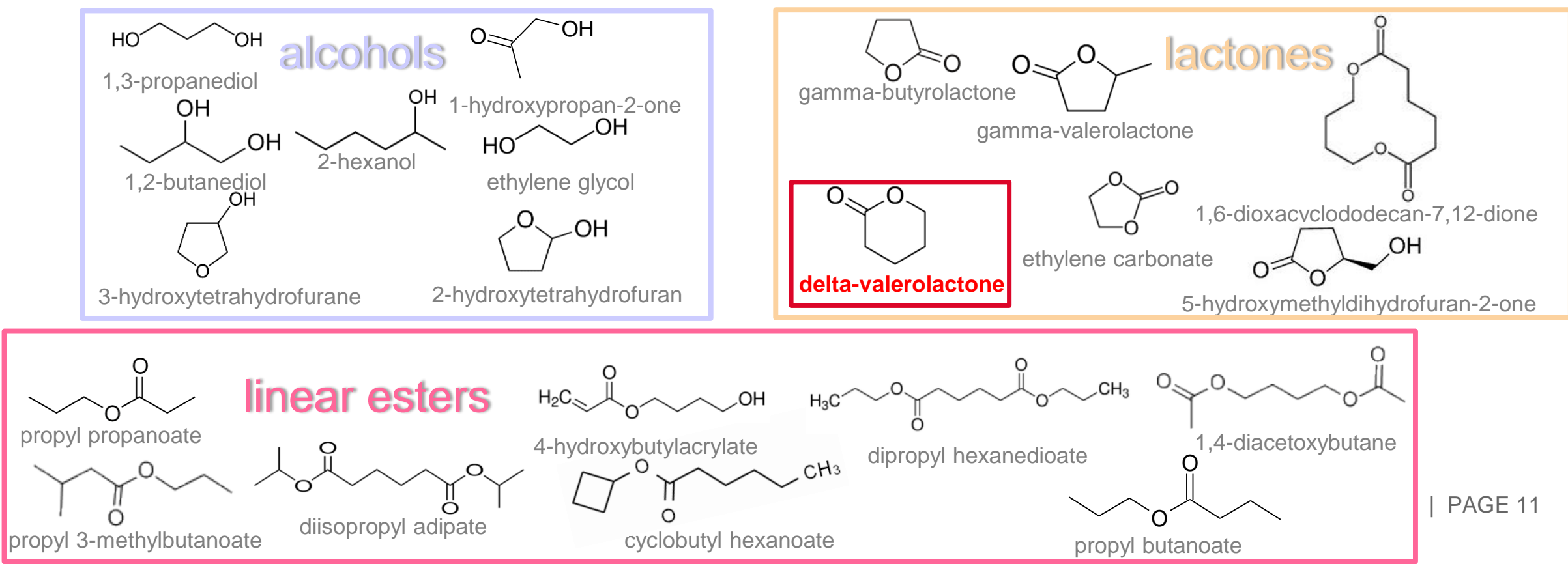


\section{ceaden}

\section{RESULTS AND DISCUSSION}

\section{Gas chromatography-mass spectrometry}

- An example of a degradation mechanism:

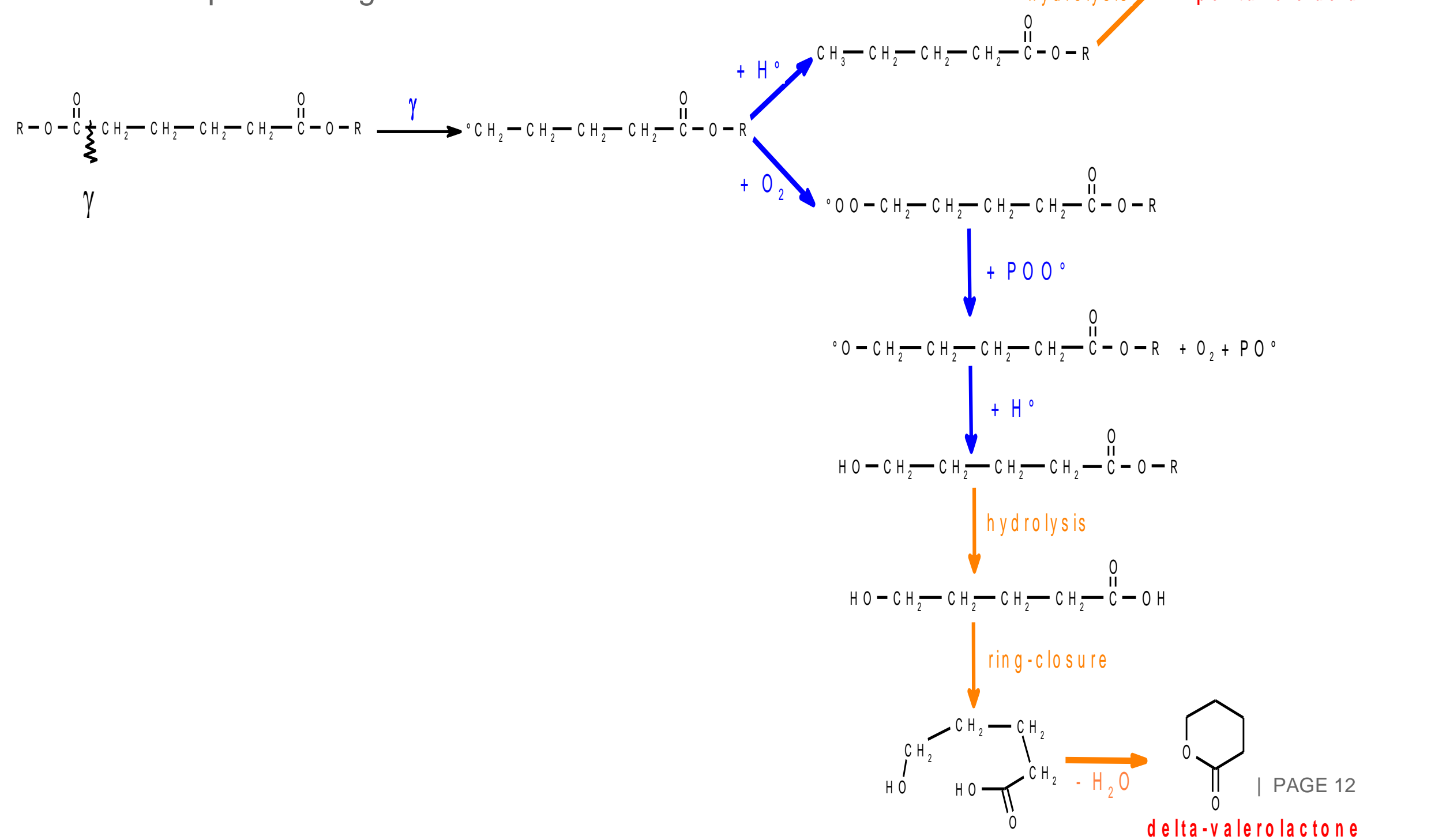




\section{ceaden concLUSION}

- Goals of the study:

- Characterizing and quantifying water-soluble molecules created by the alkaline hydrolysis of the non irradiated and irradiated PUR

- Understanding the degradation mechanisms

- PUR under radiolysis

- Irradiated PUR under hydrolysis

- Ionic chromatography + TOC analyzer = material balance, but the material balances are not complete. Solution $\rightarrow$ developing other analytical techniques such as:

- Gas chromatography coupled with mass spectrometry 


\section{ceaden concLusion}

- Results:

— New molecules detected: the knowledge of released molecules is improved

- Identification of the molecules origin

- Fragments of the polymer formula

- Compounds obtained by chain scission, chain ends oxidation, ester groups hydrolysis or/and rearrangements

=> Better understanding of the mechanisms of irradiation and of leaching

- Perspectives:

- Quantifying the molecules detected by GC-MS

- Identifying the molecules than can complex with the radionuclides

- Following the complexant release kinetics

=> Irradiated PURm hydrolysis mechanisms to be proposed 


\section{Thank you for your attention.}

\section{Do you have any questions?}

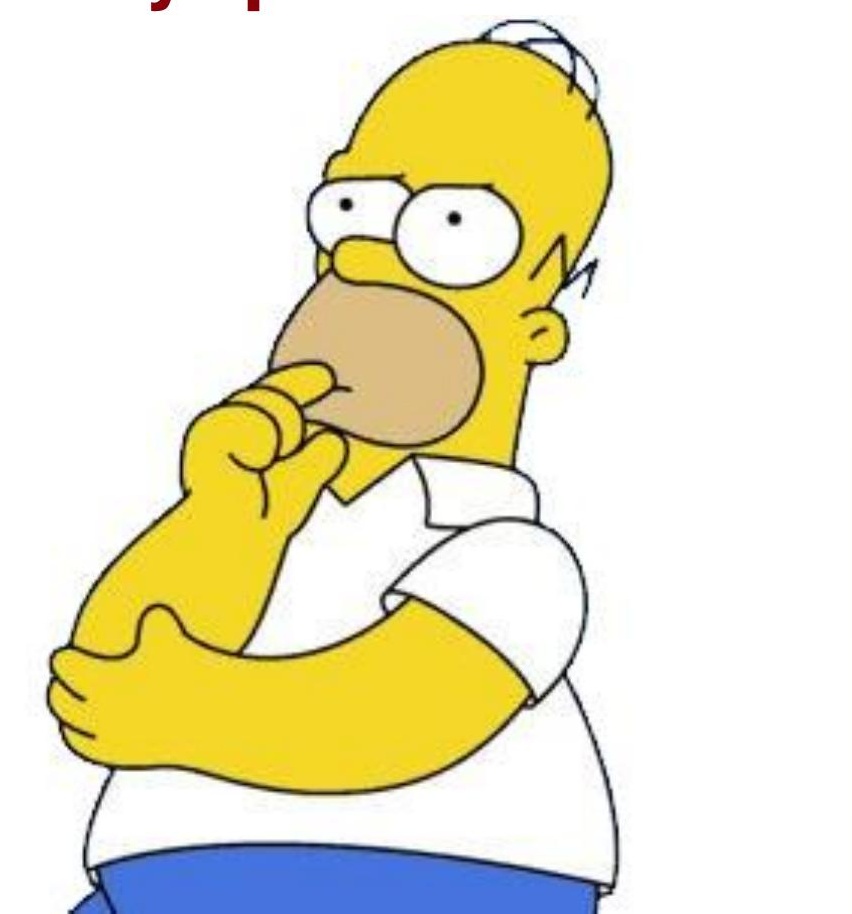

\section{ACKNOWLEDGMENT}

This work has been financed by AREVA.

Thanks to S.Rouif (IONISOS) for her helpful collaboration during irradiation.

Thanks to V. Dauvois, E. Zerki, M. Tabarant, S.Sandirin, J.L. Roujou, A.Turban, D. Durand for their ideas and technical help. 